\title{
VALORES DE REFERÊNCIA PARA O PERFIL ELETROFORÉTICO DE PROTEÍNAS SÉRICAS EM CABRAS
}

\author{
(Reference values for electrophoresis of serum proteins in goats)
}

\author{
SANTAROSA, K.T. ${ }^{1}$; ROCHA E SILVA, R.C. ${ }^{1}$; SILVA, J.B.A. ${ }^{2}$; SOTO-BLANCO, B. ${ }^{3}$ \\ ${ }^{1}$ Curso de Medicina Veterinária - Universidade Federal Rural do Semi-árido (UFERSA), Mossoró/RN; \\ ${ }^{2}$ Curso de Doutorado - FAVET/UECE, Fortaleza/CE; \\ ${ }^{3}$ Departamento de Ciências Animais - UFERSA, Mossoró/RN.
}

\begin{abstract}
RESUMO - O perfil eletroforético de proteínas séricas é uma ferramenta que pode ser utilizada como auxílio ao diagnóstico de diversas patologias. No entanto, para adequada interpretação deste exame, é necessário o estabelecimento dos valores de referência locais, uma vez que estes podem divergir daqueles obtidos em outras condições. Assim, o objetivo do presente trabalho foi determinar valores de referência para o exame eletroforético de proteínas séricas em caprinos criados no estado do Rio Grande do Norte. Foram coletadas amostras de sangue de 22 caprinos adultos negativos para o vírus da artrite e encefalite caprinas, de propriedades localizadas no município de Afonso Bezerra, RN. Foram determinados os níveis séricos de proteínas totais e das diferentes frações de proteínas separadas por eletroforese. Os resultados obtidos foram: proteínas totais - 70,0g/L; albumina - 37,0g/L; $\alpha$ globulinas - 7,63g/L; $\beta 1$-globulinas - 10,4g/L; $\beta 2$ globulinas - $10,2 \mathrm{~g} / \mathrm{L} ; \gamma$-globulinas $-4,76 \mathrm{~g} / \mathrm{L}$ e relação albumina/globulinas - 1,16. Assim, os resultados obtidos poderão ser utilizados no auxílio ao diagnóstico de doenças em caprinos.
\end{abstract}

Palavras-chave: proteinograma, eletroforese, albumina, globulina, caprinos. ABSTRACT - Electrophoretic profiles of serum proteins
can help on the diagnosis of several pathologies.
However, the establishment of local reference values
is important for accurate interpretation of this laboratory
assay, since those values may be variable depending
on local conditions. Thus, the aim of the present
research work was to determine the reference values
for eletrophoretic separation of serum proteins in goats
from Rio Grande do Norte State (RN) - Brazil - farms.
Blood samples were collected from 22 adult goats,
negative for caprine arthritis and encephalitis virus, from
farms at Afonso Bezerra city. Serum levels of total
proteins were assayed and separation of gobulins
performed by electrophoresis. The following results
were found: Total proteins, $70.0 \mathrm{~g} / \mathrm{L}$, albumin, $37.0 \mathrm{~g} /$
$\mathrm{L}$, a- globulins, $7.63 \mathrm{~g} / \mathrm{L}$, b1- globulins, $10.4 \mathrm{~g} / \mathrm{l}$, b2-
globulins, $10.2 \mathrm{~g} / \mathrm{L}$, g-globulins, $4.76 \mathrm{~g} / \mathrm{L}$, and albumin/
globulins ratio 1.16 . Thus, data from this research work may be useful as a tool on the diagnosis of goat diseases

Key-words: proteinogram, serum proteins, electrophoresis, albumin, globulin, goats.

\section{Introdução}

Os princípios da eletroforese estão baseados nos conhecimentos da composição química das proteínas e nos fatores como carga elétrica e peso molecular, que determinam sua migração eletroforética (NAOUM, 1990). A eletroforese tem sido utilizada como método de referência para o fracionamento e quantificação das proteínas séricas em bioquímica clínica (KANEKO, 1997).

$\mathrm{Na}$ eletroforese podem ser observadas várias alterações que ocorrem nas frações protéicas nos vários estados fisiológicos e nas diversas enfermidades (NAOUM, 1990). Há grande número de variáveis que influenciam o padrão eletroforético das proteínas tais como: espécie, sexo, idade, manejo dos animais, condições ambientais, tipo de meio e técnicas utilizadas na eletroforese. Além disto, existem diferenças específicas nas frações dependendo do método utilizado. Desta forma, é necessária a padronização dos valores normais do perfil eletroforético (KEAY e DOXEY, 1982), assim como das alterações que ocorrem nas diversas enfermidades em cada espécie animal (OSBALDISTON, 1972; ALENCAR FILHO, 1974).

O perfil eletroforético de proteínas séricas é uma ferramenta que pode ser utilizada como auxílio ao diagnóstico de diversas patologias. No entanto, para a adequada interpretação deste exame, é necessário o estabelecimento de valores de referência locais, uma vez que estes podem divergir daqueles obtidos em outras condições. Assim, o objetivo do presente trabalho foi determinar os valores de referência para o exame eletroforético de proteínas séricas em caprinos.

\section{Material e Método}

Foram coletadas amostras de sangue em tubos sem anticoagulante de 22 caprinos adultos, de propriedades localizadas no município de Afonso Bezerra, RN. Estes

Autor para correspondência: DCAn - UFERSA - BR 110 Km 47 - CEP 59625-900 Mossoró - Rio Grande do Norte - email: bsotoblanco@yahoo.com.br. 
Valores de referência para o perfil eletroforético de proteínas séricas em cabra

animais eram criados em sistema semi intensivo e pertenciam a um grupo uniforme de fêmeas com idades entre 2 a 4 anos, não gestantes, com programas de desverminação periódica. Todos os animais eram soro negativos para artrite e encefalite caprina a vírus, segundo teste de imunodifusão em gel de ágar. As amostras de soro foram separadas e mantidas refrigeradas, até as análises, 24 horas após.

A determinação dos níveis séricos de proteínas totais foi realizada com o auxílio de um refratômetro de uso clínico (Quimis ${ }^{\circledR}$ ).

A migração eletroforética para a separação das frações protéicas foi realizada segundo a técnica de eletroforese em gel de agarose. Foram colocados 80 $\mathrm{ml}$ de solução tampão, Tris pH 9,5 gelado, em cada uma das duas cubas. Foi aplicado 0,5ì de soro nos locais de aplicação de amostra de dois filmes de agarose (Celmgel, Celm $®)$. Em seguida, cada filme de agarose foi colocado em um porta-filme, que foi colocado nas cubas. As cubas foram ligadas na fonte, aplicando-se uma voltagem de 90 volts por 20 minutos. Em seguida os porta-filmes foram colocados sobre uma folha de papel toalha para eliminar todo o excesso da solução tampão. Os filmes foram mergulhados em um recipiente contendo $200 \mathrm{ml}$ de corante Negro de Amido a $0,2 \%$, em solução de ácido acético a $5 \%$, deixando por 5 minutos sem agitar. Posteriormente, foi retirado o excesso do corante com papel toalha e o filme foi mergulhado em um recipiente com $200 \mathrm{ml}$ de descorante ácido acético a $5 \%$, por 5 minutos. 0 excesso do descorante foi removido com papel toalha e o filme foi seco com o auxílio de um secador de cabelos comum.

A identificação e a quantificação das diferentes bandas eletroforéticas foram realizadas com auxílio de um software (DensitScan $\left.{ }^{\circledR}\right)$, após o escaneamento dos filmes corados.

Com os dados obtidos, foram calculadas as concentrações absolutas de cada banda eletroforética e da relação entre albumina e globulinas (relação $A / G$ ). A seguir, foram calculados as médias e seus respectivos desvio-padrões, e os intervalos de confiança 95\% com o auxílio do software GraphPad Instat® versão 3.01.

\section{Resultados e Discussão}

Foram verificadas cinco bandas protéicas, identificadas como albumina e á-, â1-, â2- e ã-globulinas. Os valores obtidos estão apresentados na TABELA 1.

As mesmas bandas eletroforéticas observadas neste estudo também foram descritas por KANEKO (1997). Além disto, este mesmo autor relatou que os ovinos apresentam perfil eletroforético de proteínas séricas similar ao dos caprinos. No entanto, os bovinos e as Ihamas apresentam duas bandas de $\alpha$-globulinas $e$ apenas uma de $\beta$, enquanto os eqüinos (KANEKO, 1997) e catetos (LOCHMILLER et al., 1984) apresentam duas de $\alpha$ e outras duas de $\beta$. Os cães e gatos apresentam duas bandas de $\alpha$-, $\beta$ - e $\gamma$-globulinas. Apesar dos suínos também apresentarem apenas duas bandas de globulinas como os caprinos e os ovinos, o perfil apresentado na eletroforese é bastante distinto (KANEKO, 1997).

TABELA 1 - CONCENTRAÇÕES DE PROTEÍNAS TOTAIS, ALBUMINA, $\alpha-, \beta 1-, \beta 2-$ E $\gamma$-GLOBULINAS, E RELAÇÃo ENTRE ALBUMINA E GLOBULINAS (RELAÇÃO A/G).

\begin{tabular}{lccc}
\hline \multicolumn{1}{c}{ Parâmetro } & média \pm desvio-padrão & $\begin{array}{c}\text { intervalo de confiança } \\
95 \%\end{array}$ & $\begin{array}{c}\text { valores segundo } \\
\text { KANEKO, } 1997\end{array}$ \\
\hline proteínas totais & $70,0 \pm 5,86 \mathrm{~g} / /$ & $67-73 \mathrm{~g} / \mathrm{l}$ & $64-70 \mathrm{~g} / \mathrm{l}$ \\
albumina & $37,0 \pm 5,48 \mathrm{~g} / \mathrm{l}$ & $34-39 \mathrm{~g} / \mathrm{l}$ & $27-39 \mathrm{~g} / \mathrm{l}$ \\
$\alpha$-globulinas & $7,63 \pm 2,04 \mathrm{~g} / \mathrm{l}$ & $6,7-8,5 \mathrm{~g} / \mathrm{l}$ & $5,0-7,0 \mathrm{~g} / \mathrm{l}$ \\
$\beta 1$-globulinas & $10,4 \pm 2,46 \mathrm{~g} / \mathrm{l}$ & $9,3-11,4 \mathrm{~g} / \mathrm{l}$ & $7,0-12,0 \mathrm{~g} / \mathrm{l}$ \\
$\beta 2$-globulinas & $10,2 \pm 3,74 \mathrm{~g} / \mathrm{l}$ & $8,5-11,8 \mathrm{~g} / \mathrm{l}$ & $3,0-6,0 \mathrm{~g} / \mathrm{l}$ \\
$\gamma$-globulinas & $4,76 \pm 1,38 \mathrm{~g} / /$ & $4,1-5,4 \mathrm{~g} / \mathrm{l}$ & $9,0-30,0 \mathrm{~g} / \mathrm{l}$ \\
relação A/G & $1,16 \pm 0,59$ & $0,9-1,4$ & $0,6-1,3$ \\
\hline
\end{tabular}

Apesar da semelhança no perfil eletroforético, os valores obtidos em cada uma das bandas foram um pouco superiores aos apresentados pela literatura (KANEKO, 1997). As possíveis causas das diferenças podem ser devido as metodologias utilizadas pelo autor ou devido às diferenças genéticas, manejo e alimentação dos animais avaliados. Estes fatores são fontes importantes de variação nos resultados do proteinograma, reforçando a necessidade do estabelecimento de parâmetros regionais (CANAVESSI et al., 2000).

Ao se comparar nossos dados obtidos com os citados na literatura, observa-se que há variação nos valores obtidos no proteinograma, confirmando a necessidade de se estabelecer padrões para referência local. Os resultados poderão ser utilizados no auxílio ao diagnóstico de doenças em caprinos, uma vez que diversas doenças são capazes de afetar o perfil eletroforético das proteínas séricas, com destaque as doenças infecciosas (KANEKO, 1997). Como exemplo, cita-se a infecção pelo Trypanosoma evansi, que resulta em aumento nos níveis séricos de $\gamma$-globulinas (SINGLA e JUYAL, 1992). No entanto, as doenças tóxicas podem afetar as diferentes proteínas séricas. Em bovinos alimentados com festuca infectada pelo fungo endofitico, Neotyphodium coenophialum, foi observado aumento 
na relação albumina/globulinas e redução nas frações de $\alpha$ - e $\gamma$-globulinas (SCHULTZE et al., 1999). Na intoxicação crônica por arsênico em caprinos foi verificada redução nos níveis séricos da albumina, provavelmente devido a perda desta, pela urina, em decorrência do efeito nefrotóxico (BISWAS et al., 2000).

Alguns fármacos são capazes de afetar o funcionamento do sistema imunológico e, deste modo, podem afetar o perfil eletroforético das proteínas séricas. Neste sentido, a administração de levamisol a bezerros neonatos foi capaz de elevar os níveis séricos de $\gamma$-globulinas (MOHRI et al., 2005). Além disto, a hidratação dos animais também é um importante fator, havendo aumento dos níveis séricos das proteínas devido à desidratação (KANEKO, 1997). Há variação sazonal nos níveis séricos de algumas proteínas, como foi verificado nas imunoglobulinas de caprinos Moxotó segundo relatos de JOHNSON et al. (1995).

Além da utilização no diagnóstico de algumas afecções, a avaliação das proteínas séricas, possui diversas outras finalidades. Uma destas a destacar é a avaliação da transferência de imunoglobulinas para os neonatos a partir do colostro (SANGILD, 2003). Recentemente, foi proposto o uso da eletroforese das proteínas séricas como ferramenta forense (SHARKAWY, 2003). Deste modo, os valores obtidos neste trabalho poderão ser empregados também para as finalidades citadas.

\section{Referências}

ALENCAR FILHO, R.A. Exames hematológicos no estudo das enfermidades animais. 5. Eletroforese sérica indicações clínicas. Biológico, São Paulo, v. 40, p.335336, 1974.

BISWAS, U.; SARKAR, S.; BHOWMIK, M.K.; SAMANTA, A.K.; BISWAS, S. Chronic toxicity of arsenic in goats: clinicobiochemical changes, pathomorphology and tissue residues. Small Ruminant Research, Amsterdam, v.38, p.229-235, 2000.

CANAVESSI, A.M.O.; CHIACCHIO, S.B.; SARTORI, R.; CURY, P.R. Valores do perfil eletroforético das proteínas séricas de bovinos da raça nelore (Bos indicus) criados na região de Botucatu, São Paulo: influência dos fatores etários e sexuais. Arquivos do Instituto Biológico, São Paulo, v.67, n.1, p., 2000.
JOHNSON, E.H.; KASS, P.H.; SANTA ROSA, J. Effects of energy supplementation and season on serum immunoglobulin and protein levels in Moxoto goats. Small Ruminant Research, Amsterdam, v.15, p.121-125, 1995.

KANEKO J.J. Serum proteins and dysproteinemias. In: KANEKO, J.J.; HARVEY, J.W.; BRUSS M.L. (Eds.). Clinical Biochemistry of Domestic Animals. 5th edn. San Diego: Academic Press, 1997. p.317-367.

KEAY, G; DOXEY, D.LSpecies characteristics of serum proteins demonstrated after agarose gel. Veterinary Research Communications, Dordrecht, v.5, p.263-270, 1982.

LOCHMILLER, R.L.; HELLGREN, E.C.; VARNER, L.W.; GRANT, W.E. An electrophoretic characterization of serum proteins of the collared peccary (Tayassu tajacu). Comparative Biochemistry and Physiology Part B, Vancouver, v.79, p.569-575, 1984.

MOHRI, M.; SEIFI, H.A.; ZAMANI SANI, S.H. Effects of oral administration of levamisole on non-specific immunity, serum proteins and health in normal colostrum-fed neonatal dairy calves. Comparative Clinical Pathology, v.13, p.132-136, 2005.

NAOUM, P.C. Eletroforese: técnicas e diagnósticos. São Paulo: Livraria Santos, 1990. 174p.

OSBALDISTON, G.W. Serum protein fractions in domestic animals. British Veterinary Journal, London, v.128, p.386-393, 1972.

SANGILD, P.T. Uptake of colostral immunoglobulins by the compromised newborn farm animal. Acta Veterinaria Scandinavica Supplement, Copenhagen, v.98, p.105-122, 2003.

SCHULTZE, A.E.; ROHRBACH, B.W.; FRIBOURG, H.A.; WALLER, J.C.; OLIVER, J.W. Alterations in bovine serum biochemistry profiles associated with prolonged consumption of endophyte-infected tall fescue. Veterinary and Human Toxicology, Manhattan, v.41, p.133-139, 1999.

SHARKAWY, A.A. Serum protein electrophoresis as a valuable forensic tool for animal species identification. Assiut Veterinary Medical Journal, Assint, v.49, p.279304, 2003.

SINGLA, L.D.; JUYAL, P.D. Immunomodulatory effects of levamisole against Trypanosoma evansi infection in cow-calves serum gammaglobulins. Journal of Veterinary Parasitology, New Delhi, v.6, p.9-14, 1992.

Recebido para publicação: $\quad$ 15/09/2005 Aprovado: 